\title{
25-Hydroxyvitamin D supplementation and health-service utilization for upper respiratory tract infection in young children
}

Jessica A Omand ${ }^{1,2, *}$, Teresa To ${ }^{3,4}$, Deborah L $O^{\prime}$ Connor $^{2,5}$, Patricia C Parkin ${ }^{4,6}$, Catherine S Birken $^{4,6}$, Kevin E Thorpe ${ }^{1,7}$ and Jonathon L Maguire ${ }^{1,4,6}$ on behalf of the TARGet Kids! Collaboration

'Li Ka Shing Knowledge Institute, St. Michael's Hospital, 209 Victoria Street, Toronto, ON, Canada, M5B 1T8:

${ }^{2}$ Department of Nutritional Sciences, Faculty of Medicine, University of Toronto, Toronto, ON, Canada: ${ }^{3}$ Child Health Evaluative Sciences, The Hospital for Sick Children, Toronto, ON, Canada: ${ }^{4}$ Institute of Health Policy, Management and Evaluation, University of Toronto, Toronto, ON, Canada: ${ }^{5}$ Translational Medicine, The Hospital for Sick Children, Toronto, ON, Canada: ${ }^{6}$ Division of Paediatric Medicine and the Paediatric Outcomes Research Team, The Hospital for Sick Children, Toronto, ON, Canada: ${ }^{7}$ Dalla Lana School of Public Health, University of Toronto, Toronto, ON, Canada

Submitted 11 January 2017: Final revision received 6 April 2017: Accepted 12 April 2017: First published online 5 June 2017

\begin{abstract}
Objective: Upper respiratory tract infections (URTI) are the most common and costly condition of childhood. Low vitamin D levels have been hypothesized as a risk factor for URTI. The primary objective was to determine if serum vitamin D levels were associated with health-service utilization (HSU) for URTI including hospital admission, emergency department visits and outpatient sick visits. The secondary objectives were to determine whether oral vitamin D supplementation in pregnancy or childhood was associated with HSU for URTI.

Design: Cohort study. HSU was determined by linking each child's provincial health insurance number to health administrative databases. Multivariable quasi Poisson regression was used to evaluate the association between 25-hydroxyvitamin D, vitamin D supplementation and HSU for URTI.

Setting: Toronto, Canada.

Subjects: Children participating in the TARGet Kids! network between 2008 and 2013.

Results: Healthy children aged 0-5 years ( $n$ 4962) were included; $52 \%$ were male and mean 25-hydroxyvitamin D was $84 \mathrm{nmol} / 1$ (range $11-355 \mathrm{nmol} / \mathrm{l}$ ). There were 105 (2\%), 721 (15\%) and 3218 (65\%) children with at least one hospital admission, emergency department visit or outpatient sick visit for URTI, respectively. There were no statistically significant associations between 25-hydroxyvitamin D or vitamin D supplementation and HSU for URTI.

Conclusions: A clinically meaningful association between vitamin D (continuously and dichotomized at $<50$ and $<75 \mathrm{nmol} / \mathrm{l}$ ) and HSU for URTI was not identified. While vitamin D may have other benefits for health, reducing HSU for URTI does not appear to be one of them.
\end{abstract}

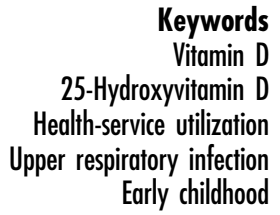

Keywords

25-Hydroxyvitamin D Health-service utilization Early childhood
Upper respiratory tract infections (URTI) are the most common infectious disease for children in North America and account for a large portion of health-service utilization (HSU) ${ }^{(1)}$. Pre-school children experience six to eight URTI per year ${ }^{(2)}$, with approximately $50 \%$ seeking medical attention in the outpatient or emergency department setting and roughly $1 \%$ requiring hospitalization ${ }^{(3-6)}$. A number of studies have suggested that low vitamin D levels may play a role in susceptibility to URTI in children. Suggested mechanisms have included improved immune and inflammatory response through T-helper cell regulation, immunoglobulin production and stimulation of the antimicrobial peptide cathelicidin $^{(7-9)}$. Two meta-analyses, including randomized controlled trials with both children and adults, found that vitamin $\mathrm{D}$ had a protective effect against respiratory tract infections $\left(\mathrm{OR}=0.64 ; 95 \% \mathrm{CI} 0 \cdot 49,0.84^{(10)}\right.$ and $\mathrm{OR}=0.582$; $95 \%$ CI $\left.0 \cdot 417,0 \cdot 812^{(11)}\right)$. However, a meta-analysis of randomized controlled trials involving only children found no association between vitamin $\mathrm{D}$ and risk of acute respiratory infections (relative risk $(\mathrm{RR})=0.79,95 \%$ CI 0.55, 1.13) ${ }^{(12)}$. 
Given the existing literature supporting a relationship between vitamin D and URTI risk, we hypothesized that children's serum 25-hydroxyvitiamin D concentration and vitamin D supplement use would be negatively associated with HSU for URTI. To our knowledge, no study has yet evaluated vitamin D status and HSU for URTI in a prospective cohort of healthy young children. Thus the primary objective of the present study was to determine whether serum 25-hydroxyvitamin concentration in early childhood was associated with HSU for URTI including: (i) any hospital admission (HA), emergency department visit (ED) and outpatient sick visit (SV; i.e. Total HSU); (ii) HA; (iii) ED; and (iv) SV. The secondary objectives were to determine whether oral vitamin D supplementation in pregnancy or childhood was associated with Total HSU, HA, ED or SV for URTI.

\section{Methods}

A cohort of healthy urban children, 0 to 5 years of age, who participated in the TARGet Kids! (The Applied Research Group for Kids) practice-based research network between December 2008 and March 2013, were included in the present study. Participants were recruited from seven large paediatric or family medicine group practices in Toronto, Canada (latitude $43.4^{\circ} \mathrm{N}$ ). Children were excluded if they had conditions affecting growth, chronic condition(s) except for asthma, or severe developmental delay $^{(13)}$. A detailed questionnaire, adapted from the Canadian Community Health Survey, was completed by the parent or guardian of each child at the time of enrolment to collect data on participant characteristics and demographics $^{(14)}$.

\section{Measurements}

\section{Exposure definitions}

The primary exposure was serum 25-hydroxyvitamin D as a continuous variable in $\mathrm{nmol} / \mathrm{l}$. Total 25 -hydroxyvitamin $\mathrm{D}$ was measured from blood serum collected during a well-child visit (between December 2008 and March 2013) using a competitive two-step chemiluminescence assay (LIAISON $25 \mathrm{OH}$ Vitamin D TOTAL Assay; DiaSorin SpA, Vercelli, Italy $)^{(15)}$ at the Mount Sinai Services Laboratory (Toronto, ON, Canada). Intra-assay imprecision of the assay was $7 \cdot 2 \%$ at a concentration of $213 \mathrm{nmol} / \mathrm{l}$ and interassay imprecision was $4.9 \%$ at $32 \mathrm{nmol} / 1,8.9 \%$ at $77 \mathrm{nmol} / 1$ and $17.4 \%$ at $213 \mathrm{nmol} / \mathrm{l}$. These values are well within acceptable limits for biochemical measurements ${ }^{(16,17)}$. 25-Hydroxyvitamin D concentration was measured continuously as well as dichotomized at $<50$ and $<75 \mathrm{nmol} / 1$, respectively, based on the American Academy of Pediatrics/ Institute of Medicine and Canadian Paediatric Society reference cut-off points ${ }^{(18-20)}$.
The secondary exposures, measured at the same visit or the first TARGet Kids! visit (if laboratory data were unavailable), were:

1. Single-nutrient oral vitamin D prenatal supplementation measured by parental report using the question: 'Did your child's biological mother take any vitamins or supplements during her pregnancy?' This captured supplementation during the entire pregnancy and was not broken down by trimester. We only included single-nutrient vitamin D supplements in order to differentiate from those women taking a prenatal multivitamin (approximately 90\% of women were taking a prenatal multivitamin).

2. Oral vitamin D supplementation in childhood measured by parental report using the following questions: 'Does your child take a vitamin D-containing supplement regularly?' and 'In a typical day, how much does your child take?' We combined the dose of vitamin D in international units (IU) from multivitamins and singlenutrient vitamin D supplements to estimate current total daily intake of supplemental vitamin D.

\section{Outcome definitions}

All residents of Ontario are insured through the Ontario Health Insurance Plan (OHIP), a universal single-payer health-care system, and are provided a unique health insurance number (OHIP number). For the current study, prospectively collected data from the TARGet Kids! practice-based research network were linked to three health administrative databases at the individual level using the encrypted OHIP number, with $98 \%$ success. This type of linkage allowed for protection of the participants' identities while examining their HSU across different databases. Linkage occurred at the Institute for Clinical Evaluative Sciences in Ontario, Canada, which is a prescribed registry under Ontario's Personal Health Information Protection Act and permits the collection of health-service data without patient consent. The health administrative databases used were:

1. the Canadian Institute for Health Information's discharge abstract database (DAD) to obtain data on HA;

2. the Canadian Institute for Health Information's National Ambulatory Care Reporting System (NACRS) to obtain data on ED; and

3. the OHIP physician claims database to obtain information on fee-for-service physician billings for SV.

The observation window for the outcomes included HSU visits that occurred $365 \mathrm{~d}$ before and after the exposure measurements (1 year before and after the date that 25-hydroxyvitamin $\mathrm{D}$ was measured for the primary analysis; and 1 year before and after the date that vitamin D supplement data were captured for the secondary analyses).

The International Classification of Diseases, 10th revision (ICD-10) defines URTI as a disorder characterized by an infectious process involving the upper respiratory tract 
(nose, paranasal sinuses, pharynx, larynx or trachea) ${ }^{(21)}$. The ICD-10 diagnostic codes were used to identify HSU for URTI in the DAD (HA) and NACRS (ED) databases. The most responsible diagnosis was used and has been shown to have the highest predictive accuracy ${ }^{(22)}$. OHIP fee-forservice physician diagnostic codes were used to define a URTI for SV. See the online supplementary material for included URTI diagnostic codes. In order to calculate Total $\mathrm{HSU}, \mathrm{HA}+\mathrm{ED}+\mathrm{SV}$ were combined.

HSU before $28 \mathrm{~d}$ of life was excluded to avoid complications from birth. Health-service episodes less than 2 weeks apart were considered a single event to avoid counting multiple visits for the same URTI. Priority was given to $\mathrm{HA}$, then $\mathrm{ED}$ and then SV.

\section{Other variables}

Covariates that might influence the relationship between 25-hydroxyvitamin D and HSU were identified a priori through a literature review and measured at the time of laboratory analysis or first TARGet Kids! visit (if laboratory data were unavailable). These included age ${ }^{(23,24)}, \operatorname{sex}^{(25)}$, number of children in the household ${ }^{(26)}$, day care/preschool attendance ${ }^{(26-28)}$ and BMI $Z$-score ${ }^{(29)}$.

Weight was measured using a precision digital scale and height was measured using a length board for children under 2 years and a stadiometer (SECA) for children over 2 years. BMI was calculated as weight in kilograms divided by the square of height in metres $\left(\mathrm{kg} / \mathrm{m}^{2}\right)^{(30)}$. BMI $Z$-scores were calculated using the WHO growth standards ${ }^{(31)}$.

\section{Statistical analysis}

The total numbers of HA, ED and SV for URTI were described as counts. For the primary analysis, multivariable quasi Poisson regression was used to account for overdispersion of the data. The associations between 25-hydroxyvitamin D and (i) Total HSU, (ii) HA, (iii) ED and (iv) SV for URTI were tested. An offset was used to account for variation in the window of observation. The models were adjusted by the covariates specified above regardless of statistical significance to avoid bias that can result from standard variable selection techniques ${ }^{(32,33)}$. Sensitivity analyses were performed repeating the primary analysis but including only children with 25-hydroxyvitamin D levels below $<50$ and $<75 \mathrm{nmol} / \mathrm{l}$ based on the Academy of Pediatrics/Institute of Medicine and Canadian Paediatric Society reference cut-off points, respectively, to evaluate consistency of findings ${ }^{(18-20)}$.

We assessed for multicollinearity for all covariates using the variance inflation factor ${ }^{(34)}$. All variance inflation factors were $<5$, so we concluded that multicollinearity was unlikely to be a problem in the current analysis ${ }^{(34)}$.

Circulating 25-hydroxyvitamin D concentration varied from season to season, with higher levels during the summer and lower levels during the winter. To account for variability in the date of blood sampling, we adjusted the exposure (25-hydroxyvitamin D) for seasonal variability using the sine curve method described by Zhang et al. ${ }^{(35)}$. This allowed us to adjust for seasonal variation in vitamin D. Considering HSU was measured in all seasons over a 2-year period and 25-hydroxyvitamin D was seasonally adjusted, season is unlikely to be a potential confounder and was not included as a covariate.

Non-linearity was explored through graphical presentation of the data and spline analysis using three knots. A likelihood ratio test was conducted between the linear and non-linear models (nested models) to compare the goodness-of-fit. A $P$ value of 0.96 meant we did not reject the linear model.

Multiple imputations were performed, using transcan in the $\mathrm{R}$ package Hmisc, on covariates (number of children in the household, day care/pre-school attendance and BMI Z-score) in order to overcome bias that can result from missing data ${ }^{(33)}$. No variables had more than $5 \%$ missing data. We did not impute missing data for the exposures or the outcomes.

For the secondary analyses, the above multivariable quasi Poisson regression models were repeated but with vitamin D supplementation in pregnancy and childhood as the exposure variables with the same covariates and HSU outcomes.

All $P$ values were two-tailed and $P<0.05$ was considered statistically significant. All statistical analyses were conducted with the statistical software packages SAS version 9.3 and $R$ version 3.3 .

\section{Results}

Of the 4962 children who met the inclusion criteria and provided consent to participate, 2926 had 25-hydroxyvitamin $\mathrm{D}$ measured and were included in the primary analysis (see Fig. 1). In the secondary analyses which evaluated maternal vitamin D supplementation and child vitamin D supplementation, 4672 and 4132 children were included, respectively. Baseline characteristics of children with and without laboratory testing are outlined in Table 1. Children with laboratory testing were slightly older and

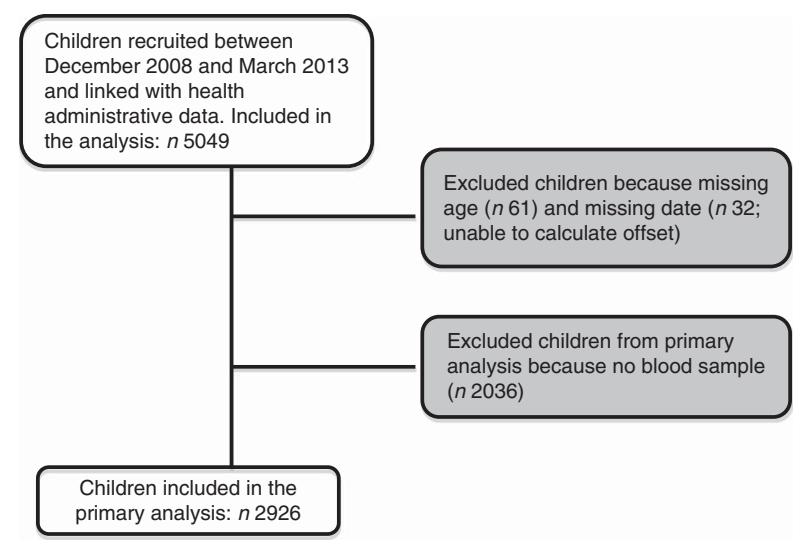

Fig. 1 Selection of participants for the present study 
Table 1 Sociodemographic characteristics of the TARGet Kids! cohort, Toronto Canada, 2008-2013

\begin{tabular}{|c|c|c|c|c|c|c|c|c|c|c|c|c|}
\hline & \multicolumn{4}{|c|}{ All children ( $n$ 4962) } & \multicolumn{4}{|c|}{$\begin{array}{l}\text { Children with serum } \\
\text { 25-hydroxyvitamin D measured ( } n \text { 2926) }\end{array}$} & \multicolumn{4}{|c|}{$\begin{array}{l}\text { Children without serum } \\
\text { 25-hydroxyvitamin D measured ( } n \text { 2036) }\end{array}$} \\
\hline & $n$ & $\%$ & Mean & Range & $n$ & $\%$ & Mean & Range & $n$ & $\%$ & Mean & Range \\
\hline \multicolumn{13}{|l|}{ Age } \\
\hline$<2$ years & 2003 & 40 & & & 1036 & 35 & & & 967 & 48 & & \\
\hline $2-4$ years & 1417 & 29 & & & 887 & 30 & & & 530 & 26 & & \\
\hline$>4$ years & 1542 & 31 & & & 1003 & 34 & & & 539 & 26 & & \\
\hline Sex, male & 2601 & 52 & & & 1559 & 53 & & & 1042 & 51 & & \\
\hline BMI Z-score & & & 0.13 & $-4.72-4.86$ & & & 0.14 & $-3.99-4.36$ & & & 0.13 & $-4 \cdot 72-4 \cdot 86$ \\
\hline \multicolumn{13}{|l|}{ Maternal education } \\
\hline Primary school & 55 & 1 & & & 33 & 1 & & & 22 & 1 & & \\
\hline High school & 442 & 9 & & & 252 & 9 & & & 190 & 10 & & \\
\hline College or university & 4312 & 90 & & & 2550 & 90 & & & 1762 & 89 & & \\
\hline Median neighbourhood-level income before tax (\$CAN) & & & 59189 & $0-335039$ & & & 58596 & $0-335039$ & & & 60036 & $0-268530$ \\
\hline \multicolumn{13}{|l|}{ Ethnicity } \\
\hline $\begin{array}{l}\text { European } \\
\text { East Asian }\end{array}$ & $\begin{array}{r}3228 \\
338\end{array}$ & $\begin{array}{r}68 \\
7\end{array}$ & & & $\begin{array}{r}1865 \\
203\end{array}$ & $\begin{array}{r}67 \\
7\end{array}$ & & & $\begin{array}{r}1363 \\
135\end{array}$ & $\begin{array}{r}69 \\
7\end{array}$ & & \\
\hline South-East Asian/South Asian & 504 & 11 & & & 302 & 11 & & & 202 & 10 & & \\
\hline West Asian & 83 & 2 & & & 46 & 2 & & & 37 & 2 & & \\
\hline African/Caribbean & 321 & 7 & & & 198 & 7 & & & 123 & 6 & & \\
\hline Latin American & 204 & 4 & & & 121 & 4 & & & 83 & 4 & & \\
\hline North American Aboriginal & 54 & 1 & & & 36 & 1 & & & 18 & 1 & & \\
\hline Oceania & 18 & 0.4 & & & 11 & 0.4 & & & 7 & 0.4 & & \\
\hline Prenatal supplementation multivitamin, yes & 4127 & 88 & & & 2506 & 91 & & & 1621 & 84 & & \\
\hline $\begin{array}{l}\text { Prenatal supplementation, single-nutrient vitamin } D \text {, yes } \\
\text { Child vitamin D supplements (combined dose from } \\
\text { multivitamins and single-nutrient vitamin D) (uq/d) }\end{array}$ & 482 & 10 & 4.9 & $0-70 \cdot 0$ & 301 & 11 & $5 \cdot 6$ & $0-70 \cdot 0$ & 181 & 9 & 3.9 & $0-70 \cdot 0$ \\
\hline $\begin{array}{l}\text { multivitamins and single-nutrient vitamin D) }(\mu \mathrm{g} / \mathrm{d}) \\
\text { Child vitamin D supplements (combined dose from } \\
\text { multivitamins and single-nutrient vitamin D) (IU/d) }\end{array}$ & & & 196 & $0-2800$ & & & 222 & $0-2800$ & & & 157 & $0-2800$ \\
\hline $\begin{array}{l}\text { Child in day care, yes } \\
25-\text { Hydroxyvitamin } D(\mathrm{nmol} / \mathrm{l})\end{array}$ & 1911 & 41 & 84 & $11-355$ & 1176 & 42 & 84 & $11-355$ & 735 & 38 & N/A & \\
\hline \multicolumn{13}{|l|}{$\begin{array}{l}\text { Number of hospital admissions per child during } \\
\text { observation window for URTI }\end{array}$} \\
\hline 0 & 4857 & 98 & & & 2865 & 98 & & & 1992 & 98 & & \\
\hline $1+$ & 105 & $2 \cdot 1$ & & & 61 & $2 \cdot 1$ & & & 44 & 2.05 & & \\
\hline \multicolumn{13}{|l|}{$\begin{array}{l}\text { Number of emergency department visits per child } \\
\text { during observation window for URTIt }\end{array}$} \\
\hline 0 & 4241 & 85 & & & 2474 & 85 & & & 1767 & 87 & & \\
\hline 1 & 569 & 11 & & & 353 & 12 & & & 216 & 11 & & \\
\hline 2 & 115 & 2 & & & 70 & 2 & & & 45 & 2 & & \\
\hline \multirow{2}{*}{\multicolumn{13}{|c|}{$\begin{array}{l}\text { Number of outpatient sick visits per child during } \\
\text { observation window for URTIt }\end{array}$}} \\
\hline & & & & & & & & & & & & \\
\hline 0 & 1744 & 35 & & & 1016 & 35 & & & 728 & 36 & & \\
\hline 1 & 1343 & 27 & & & 775 & 26 & & & 568 & 28 & & \\
\hline 2 & 830 & 17 & & & 501 & 17 & & & 329 & 16 & & \\
\hline 3 & 444 & 9 & & & 267 & 9 & & & 177 & 9 & & \\
\hline 4 & 249 & 5 & & & 155 & 5 & & & 94 & 5 & & \\
\hline 5 & 141 & 3 & & & 77 & 3 & & & 64 & 3 & & \\
\hline $6+$ & 211 & 4 & & & 135 & 5 & & & 76 & 4 & & \\
\hline
\end{tabular}

URTI, upper respiratory tract infection; ID, identification number.

${ }^{*} 110 / 517(21 \%)$ of all hospital admissions were related to URTI (429 with unique ID).

(25)

$\$ 7577 / 39429(19 \%)$ of all outpatient sick visits were related to URTI (4940 with unique ID). 


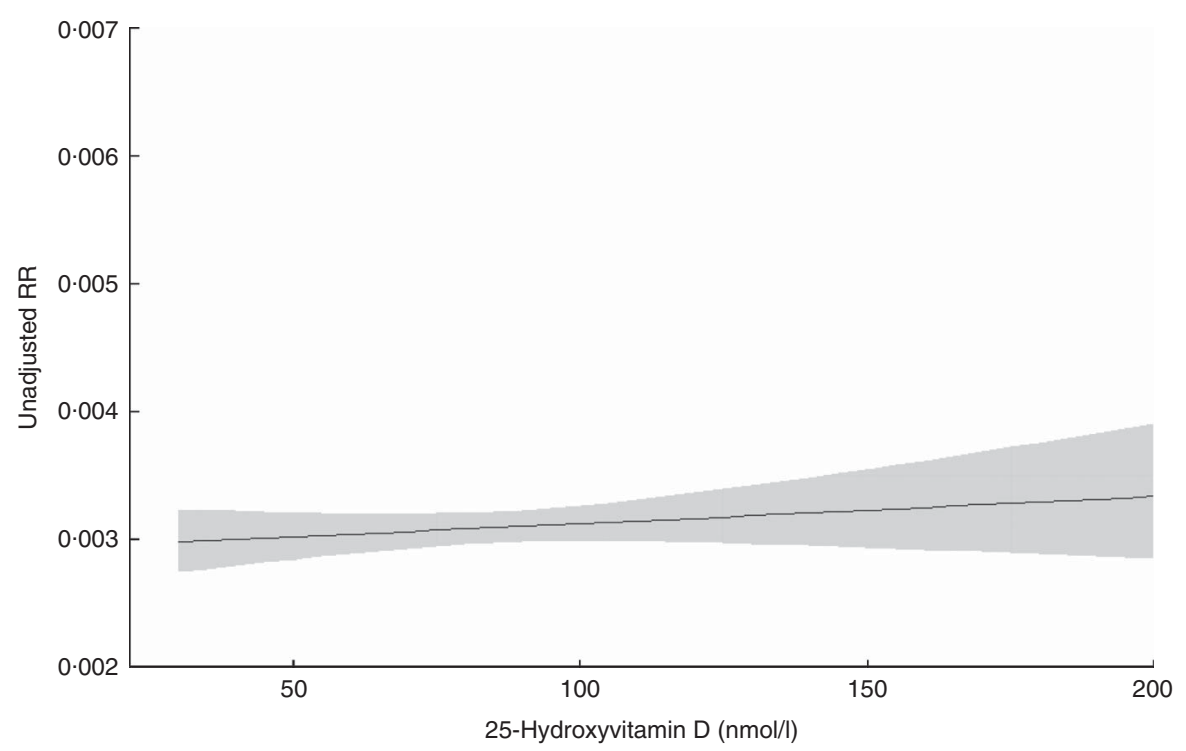

Fig. 2 Unadjusted relative risk (RR) of 25-hydroxyvitamin $\mathrm{D}$ concentration (in $10 \mathrm{nmol} / \mathrm{l}$ increments) and total health-service utilization for upper respiratory tract infections in a 2-year period in the TARGet Kids! cohort, Toronto, Canada, 2008-2013. represents the line of best fit for the data and the grey area represents the $95 \% \mathrm{Cl}$

were more likely to take a vitamin D-containing supplement; otherwise there was no clinically meaningful difference between the two groups. Fifty-two per cent of the participants were male and mean 25-hydroxyvitamin D was 84 (sD 29.7) nmol/l (range 11-355 nmol/l). 25-Hydroxyvitamin D levels below 50 and $75 \mathrm{nmol} / 1$ were found in 218 and 1267 children, respectively. Ten per cent of mothers took a single-nutrient vitamin D supplement during pregnancy. Forty-seven per cent of children were regularly consuming a vitamin D-containing supplement (mean dose was 4.9 (sD 6.9) $\mu \mathrm{g} / \mathrm{d}$ (196 (SD 276) IU/d)).

During the observation period, 4896 (97\%) children had at least one HSU of which 19\% were for URTI, 431 (9\%) children had at least one HA of which $21 \%$ were for URTI, 2191 (44\%) children had at least one ED of which $23 \%$ were for URTI, and 4883 (about 98\%) children had at least one SV of which $19 \%$ were for URTI.

For the primary analysis, we evaluated whether serum 25-hydroxyvitamin D concentration was associated with HSU for URTI. No statistically significant association was found in the unadjusted or adjusted models between 25-hydroxyvitamin $\mathrm{D}$ (in $10 \mathrm{nmol} / 1$ increments) and Total HSU (adjusted RR $(\mathrm{aRR})=1.01 ; 95 \%$ CI 0.99, 1.02; see Fig. 2), HA (aRR $=1 \cdot 01 ; 95 \%$ CI $0 \cdot 92,1 \cdot 10)$, ED $(\mathrm{aRR}=0.99 ; 95 \% \mathrm{CI} 0.96,1 \cdot 02)$ or SV $(\mathrm{aRR}=1 \cdot 01 ; 95 \% \mathrm{CI}$ 1.00, 1.02; see Tables 2 and 3).

In the sensitivity analysis, no statistically significant association was found in the unadjusted or adjusted models between 25-hydroxyvitamin D (in $10 \mathrm{nmol} / \mathrm{l}$ increments) and Total HSU among children with 25-hydroxyvitamin D levels $<50 \mathrm{nmol} / \mathrm{l}(\mathrm{aRR}=0.94 ; 95 \% \mathrm{CI}$ $0 \cdot 81,1.09)$ and $<75 \mathrm{nmol} / \mathrm{l}(\mathrm{aRR}=0.98 ; 95 \% \mathrm{CI} 0.93,1.03)$.

Further, no statistically significant associations were identified between prenatal vitamin D supplementation and Total HSU, HA, ED or SV (see Table 2). Similarly, no statistically significant associations were found between child vitamin D supplementation (in $2.5 \mu \mathrm{g} / \mathrm{d}$ (100 IU/d) increments) and Total HSU, HA, ED or SV (see Table 2).

\section{Discussion}

We conducted a cohort study to evaluate the relationship between children's 25-hydroxyvitamin D concentration, prenatal and child vitamin D supplement use and HSU for URTI. Given that URTI in young children is the most common reason for seeking health care, understanding this relationship could result in important preventive benefits. The reasons for HA, ED visits and SV in the present study were similar to those in other North American studies ${ }^{(36)}$, but we did not find clinically meaningful associations between children's serum vitamin D level, prenatal or child vitamin D supplementation and HSU for URTI. To our knowledge no study has yet evaluated vitamin D status and HSU for URTI in a cohort of healthy young children.

Other studies which have evaluated the association between vitamin D status and URTI have produced mixed results ${ }^{(10-12)}$. Two meta-analyses of randomized controlled trials including both adults and children found that vitamin $D$ had a protective effect against respiratory tract infections ${ }^{(10,11)}$. Another meta-analysis that focused on randomized controlled trials in children found no association between 25-hydroxyvitamin D and risk of acute respiratory infections ${ }^{(12)}$.

Two randomized controlled trials have assessed HSU following vitamin D supplementation in pregnancy. Griffiths et al. found no evidence that prenatal vitamin D 
supplementation (placebo, $20 \mu \mathrm{g} / \mathrm{d}(800 \mathrm{IU} / \mathrm{d}$ ) or a single bolus of $5000 \mu \mathrm{g}$ (200 $000 \mathrm{IU})$ ) from 27 weeks to delivery influenced overall HSU in children from in London, England in the first 3 years ${ }^{(2)}$. They also found no association between 25 -hydroxyvitamin $\mathrm{D}$ concentrations in the children at age 3 years ( $n$ 65) and HSU. However, their study was limited by small sample size and only a small number of subjects had adequate $(>50 \mathrm{nmol} / \mathrm{l})$ vitamin $\mathrm{D}$ status at delivery ${ }^{(18)}$. In Auckland, New Zealand, Grant et al. found an association between vitamin D supplementation during the last trimester of pregnancy and the first 6 months of infancy (placebo/placebo, $40 / 10 \mu \mathrm{g} / \mathrm{d}$ $(1000 / 400 \mathrm{IU} / \mathrm{d})$ or $80 / 20 \mu \mathrm{g} / \mathrm{d}(2000 / 800 \mathrm{IU} / \mathrm{d}))$ among 260 mother-child dyads and reduced primary-care visits for acute respiratory infections from 6 to 18 months $(P=0.048)$ for higher-dose vitamin D $v$. placebo $^{(37,38)}$. However, they had HSU data only up to 18 months and combined data from different sources to determine the outcome, including parent report up to 6 months of age, hospitalization data up to 12 months and primary-care visit data up to 18 months of age ${ }^{(37)}$. In comparison, the current study had HSU outcome data over a 2-year period from three databases including information on HA, ED and SV ( 1 year before and 1 year after the exposures were measured). Also, the mean 25-hydroxyvitamin D concentration at 18 months in Grant et al.'s paper was 63, 61 and $59 \mathrm{nmol} / \mathrm{l}$ in the placebo, low- and high-dose arms, respectively $(n 221)^{(37)}$, and these are lower than the mean 25-hydroxyvitmain D level in the current study ( $84 \mathrm{nmol} / 1, n$ 2926).

Strengths of the current study included: a relatively large sample size of healthy young children, with nearly 3000 serum 25-hydroxyvitmain D measurements; HSU data on all participants with sufficient power to detect a small association; detailed questionnaire data on vitamin $\mathrm{D}$ supplementation; as well as data on numerous potential confounders ${ }^{(39,40)}$. Further, the study was able to link clinical data from a large cohort study and health administrative data from a publicly funded health-care system.

Limitations of the present study include its observational nature, thus causality cannot be inferred. Second, health administrative data were not collected for the purposes of doing research and thus the accuracy of physician billings may have led to misclassification of the outcome. However, the use of the most responsible diagnosis has been shown to have the highest predictive accuracy and lowest likelihood of misclassification ${ }^{(22)}$. Third, we were unable to measure the dose of or adherence to vitamin D supplements taken during pregnancy and thus we were unable to determine whether a dose-relationship exists between prenatal supplementation and HSU. Forth, OHIP fee-for-service physician billing data for outpatient sick visits are limited to one diagnosis per encounter and this may have resulted in missed outcomes. Finally, the mean 25-hydroxyvitamin D concentration in the present population was $84 \mathrm{nmol} / 1$ (range $11-355 \mathrm{nmol} / \mathrm{l}$ ), which is 
Table 3 Quasi Poisson regression model for adjusted association between 25-hydroxyvitamin D and health-service utilization (HSU) for upper respiratory tract infection (URTI), TARGet Kids! cohort, Toronto, Canada, 2008-13

\begin{tabular}{|c|c|c|c|c|c|c|c|c|}
\hline & \multicolumn{2}{|c|}{$\begin{array}{c}\text { Any HSU for URTI } \\
\text { (Total HSU) }\end{array}$} & \multicolumn{2}{|c|}{$\begin{array}{l}\text { Hospital admissions } \\
\text { (HA) for URTI }\end{array}$} & \multicolumn{2}{|c|}{$\begin{array}{c}\text { Emergency } \\
\text { department visits (ED) } \\
\text { for URTI }\end{array}$} & \multicolumn{2}{|c|}{$\begin{array}{l}\text { Outpatient sick visits } \\
\text { (SV) for URTI }\end{array}$} \\
\hline & aRR & $95 \% \mathrm{Cl}$ & aRR & $95 \% \mathrm{Cl}$ & aRR & $95 \% \mathrm{Cl}$ & aRR & $95 \% \mathrm{Cl}$ \\
\hline Serum 25 -hydroxyvitamin D (10 nmol/l change) & 1.01 & $0.99,1.02$ & 1.01 & $0.92,1.10$ & 0.99 & $0.96,1.02$ & 1.01 & $1.00,1.02$ \\
\hline BMI Z-score ( 0.5 unit change) & $1 \cdot 04^{*}$ & $1.02,1.06$ & 1.09 & $0.97,1.23$ & $1.09^{*}$ & $1.04,1.14$ & $1.03^{*}$ & $1.01,1.05$ \\
\hline Age $>4$ years (ref. $=<2$ years) & $0.62 \dagger$ & $0.55,0.69$ & 0.64 & $0.31,1.29$ & 0.56 & $0.43,0.73$ & 0.62 & $0.56,0.70$ \\
\hline Age $2-4$ years (ref. $=<2$ years) & $0.80 \ddagger$ & $0.72,0.88$ & 0.95 & $0.29,1.85$ & 0.71 & $0.55,0.92$ & 0.81 & $0.72,0.90$ \\
\hline Siblings, 0 (ref. = 1 sibling) & 1.03 & $0.94,1.12$ & 0.72 & $0.41,1.30$ & 1.13 & $0.91,1.40$ & 1.02 & $0.93,1.12$ \\
\hline Siblings, 2 (ref. = 1 sibling) & 0.98 & $0.86,1.11$ & 0.44 & $0.15,1.28$ & 0.72 & $0.50,1.04$ & 1.01 & $0.89,1.16$ \\
\hline Siblings, 3+ (ref. = 1 sibling) & $1 \cdot 19$ & $0.96,1.48$ & 1.50 & $0.43,5.18$ & 1.28 & $0.76,2 \cdot 17$ & 1.18 & $0.94,1.48$ \\
\hline Gender (ref. = male) & 0.93 & $0.86,1.01$ & 0.87 & $0.52,1.45$ & 0.72 & $0.59,0.88$ & 0.96 & $0.88,1.04$ \\
\hline Day care $($ ref. $=$ no) & $1.20 \S$ & $1 \cdot 10,1 \cdot 30$ & 2.04 & $1.17,3.56$ & 1.21 & $0.98,1.50$ & 1.19 & $1.09,1.30$ \\
\hline
\end{tabular}

aRR, adjusted relative risk; ref., reference category.

${ }^{*} \mathrm{~A} 0.5$ unit increase in BMI Z-score was associated with a $4 \%$ increased incidence rate of Total HSU for URTI, $9 \%$ increased incidence rate of ED for URTI and $3 \%$ increased incidence rate of SV for URTI.

†Children aged $>4$ years had a $38 \%$ lower risk of incidence rate of Total HSU for URTI compared with children aged $<2$ years.

¥Children aged $2-4$ years had a $20 \%$ lower risk of incidence rate of Total HSU for URTI compared with children aged $<2$ years.

§Attending day care was associated with a $20 \%$ increased incidence rate of Total HSU for URTI compared with children who did not attend day care.

similar to other national studies, but may not have been sufficiently low to demonstrate an association ${ }^{(41,42)}$. However, in a sensitivity analysis, we did not identify an association with HSU in the population of children ( $n$ 218) with 25-hydroxyvitamin D concentration below $50 \mathrm{nmol} / \mathrm{l}$.

The results from the current study do not support the hypothesis that children's serum 25-hydroxyvitiamin D concentration or vitamin D supplement use (both during pregnancy and childhood) is negatively associated with HSU for URTI, with parameter estimates near null and relatively tight confidence limits. Studies in children with higher risk of low 25-hydroxyvitamin D concentrations or combined mother/infant supplementation may be necessary to demonstrate an impact on HSU for URTI.

\section{Conclusion}

While vitamin D may be a potential preventive intervention for URTI, in the present study we found no evidence to support an association between vitamin $\mathrm{D}$ status (continuously and dichotomized at $<50$ and $<75 \mathrm{nmol} / \mathrm{l}$ ), vitamin D supplementation in pregnancy or childhood and HSU for URTI in children. However, most of the participants in the study had adequate vitamin D status.

\section{Acknowledgements}

Acknowledgments: The authors thank all of the participating families for their time and involvement in TARGet Kids! and are grateful to all practitioners who are currently involved in the TARGet Kids! practice-based research network. Financial support: This work was supported by The Ontario Lung Association, Ontario Thoracic Society grant-in-aid programme. Funding to support TARGet Kids! was provided by multiple sources including the Canadian Institutes for Health Research (CIHR), namely the Institute of Human
Development, Child and Youth Health and the Institute of Nutrition, Metabolism and Diabetes, as well as the St. Michael's Hospital Foundation. Funding to support J.A.O. was provided by the CIHR doctoral award at St. Michael's Hospital and the Clinician Scientist Training Program (CSTP) at the Hospital for Sick Children. Funding agencies had no role in the design, collection, analyses or interpretation of the results of this study or in the preparation, review or approval of the manuscript. This study was supported by the Institute for Clinical Evaluative Sciences (ICES), which is funded by an annual grant from the Ontario Ministry of Health and Long-Term Care (MOHLTC). The opinions, results and conclusions reported in this paper are those of the authors and are independent from the funding sources. No endorsement by ICES or the Ontario MOHLTC is intended or should be inferred. Parts of this material are based on data and information compiled and provided by the Canadian Institute for Health Information (CIHI). However, the analyses, conclusions, opinions and statements expressed herein are those of the authors, and not necessarily those of CIHI. Conflict of interest: The authors have no conflicts of interest or financial relationships relevant to this article to disclose. Authorship: J.A.O. and J.L.M. designed the research study. T.T., D.L.O., P.C.P. and C.S.B. helped to refine the study design. J.A.O., J.L.M. and K.E.T. analysed the data. All authors contributed to the interpretation of results. J.A.O. and J.L.M. drafted the manuscript. All authors read and approved the final manuscript. J.A.O. had full access to all of the data in the study and takes responsibility for the integrity of the data and the accuracy of the data analysis. Ethics of buman subject participation: This study was approved by the Hospital for Sick Children Research Ethics Board and Institute for Clinical Evaluative Sciences (ICES). All TARGet Kids! participating parents provided consent for their child's data to be linked with health administrative data. 
TARGet Kids! Collaboration. Co-Leads: Catherine S. Birken, Jonathon L. Maguire. Scientific Committee: Kawsari Abdullah, Yamna Ali, Laura N. Anderson, Imaan Bayoumi, Cornelia M. Borkhoff, Sarah Carsley, Shiyi Chen, Yang Chen, Denise Darmawikarta, Cindy-Lee Dennis, Karen Eny, Stephanie Erdle, Kayla Furlong, Kanthi Kavikondala, Christine Koroshegyi, Christine Kowal, Grace Jieun Lee, Dalah Mason, Jessica Omand, Patricia C. Parkin, Navindra Persaud, Lesley Plumptre, Meta van den Heuvel, Shelley Vanderhout, Peter Wong, Weeda Zabih. Site Investigators: Murtala Abdurrahman, Barbara Anderson, Kelly Anderson, Gordon Arbess, Jillian Baker, Tony Barozzino, Sylvie Bergeron, Dimple Bhagat, Nicholas Blanchette, Gary Bloch, Joey Bonifacio, Ashna Bowry, Anne Brown, Jennifer Bugera, Douglas Campbell, Sohail Cheema, Elaine Cheng, Brian Chisamore, Ellen Culbert, Karoon Danayan, Paul Das, Mary Beth Derocher, Anh Do, Michael Dorey, Kathleen Doukas, Anne Egger, Allison Farber, Amy Freedman, Sloane Freeman, Keewai Fung, Sharon Gazeley, Charlie Guiang, Dan Ha, Curtis Handford, Laura Hanson, Hailey Hatch, Teresa Hughes, Sheila Jacobson, Lukasz Jagiello, Gwen Jansz, Paul Kadar, Tara Kiran, Lauren Kitney, Holly Knowles, Bruce Kwok, Sheila Lakhoo, Margarita Lam-Antoniades, Eddy Lau, Fok-Han Leung, Alan Li, Jennifer Loo, Joanne Louis, Sarah Mahmoud, Roy Male, Vashti Mascoll, Rosemary Moodie, Julia Morinis, Maya Nader, Sharon Naymark, Patricia Neelands, James Owen, Jane Parry, Michael Peer, Kifi Pena, Marty Perlmutar, Navindra Persaud, Andrew Pinto, Tracy Pitt, Michelle Porepa, Vikky Qi, Nasreen Ramji, Noor Ramji, Jesleen Rana, Alana Rosenthal, Katherine Rouleau, Janet Saunderson, Rahul Saxena, Vanna Schiralli, Michael Sgro, Hafiz Shuja, Susan Shepherd, Hafiz Shuja, Barbara Smiltnieks, Cinntha Srikanthan, Carolyn Taylor, Suzanne Turner, Fatima Uddin, Joanne Vaughan, Thea Weisdorf, Sheila Wijayasinghe, Peter Wong, Anne Wormsbecker, Ethel Ying, Elizabeth Young, Michael Zajdman, Ian Zenlea. Advisory Committee: Eddy Lau, Andreas Laupacis, Patricia C. Parkin, Michael Salter, Peter Szatmari, Shannon Weir. Research Team: Charmaine Camacho, Arthana Chandraraj, Dharma Dalwadi, Ayesha Islam, Thivia Jegathesan, Tarandeep Malhi, Megan Smith, Laurie Thompson. Applied Health Research Centre: Christopher Allen, Bryan Boodhoo, Judith Hall, Peter Juni, Gerald Lebovic, Karen Pope, Jodi Shim, Kevin Thorpe. Mount Sinai Services Laboratory: Azar Azad.

\section{Supplementary material}

To view supplementary material for this article, please visit https://doi.org/10.1017/S1368980017000921

\section{References}

1. Heikkinen T \& Järvinen A (2003) The common cold. Lancet 361, 51-59.
2. Griffiths M, Goldring S, Griffiths C et al. (2015) Effects of pre-natal vitamin D supplementation with partial correction of vitamin D deficiency on early life healthcare utilisation: a randomised controlled trial. PLoS One 10, $\mathrm{e} 0145303$.

3. Carabin H, Gyorkos TW, Soto JC et al. (1999) Estimation of direct and indirect costs because of common infections in toddlers attending day care centers. Pediatrics 103, 556-564.

4. Lambert SB, Allen KM, Carter RC et al. (2008) The cost of community-managed viral respiratory illnesses in a cohort of healthy preschool-aged children. Respir Res $\mathbf{9}, 11$.

5. Lang M (2009) Health implications of children in child care centres. Part B: Injuries and infections. Paediatr Child Health 14, 40-43.

6. Haskins R (1989) Acute illness in day care: how much does it cost? Bull NY Acad Med 65, 319-343.

7. Gombart AF, Borregaard N \& Koeffler HP (2005) Human cathelicidin antimicrobial peptide (CAMP) gene is a direct target of the vitamin $\mathrm{D}$ receptor and is strongly up-regulated in myeloid cells by 1,25-dihydroxyvitamin $\mathrm{D}_{3}$. FASEB J $\mathbf{1 9}$, 1067-1077.

8. Mahon BD, Wittke A, Weaver V et al. (2003) The targets of vitamin $\mathrm{D}$ depend on the differentiation and activation status of CD4 positive T cells. J Cell Biochem 89, 922-932.

9. Hewison M (2012) An update on vitamin D and human immunity. Clin Endocrinol (Oxf) 76, 315-325.

10. Bergman P, Lindh AU, Bjorkhem-Bergman L et al. (2013) Vitamin D and respiratory tract infections: a systematic review and meta-analysis of randomized controlled trials. PLoS One 8, e65835.

11. Charan J, Goyal JP, Saxena D et al. (2012) Vitamin D for prevention of respiratory tract infections: a systematic review and meta-analysis. I Parmacol Pharmacother 3, 300-303.

12. Xiao L, Xing C, Yang Z et al. (2015) Vitamin D supplementation for the prevention of childhood acute respiratory infections: a systematic review of randomised controlled trials. BMJ 114, 1026-1034.

13. Carsley S, Borkhoff CM, Maguire JL et al. (2015) Cohort profile: The Applied Research Group for Kids (TARGet Kids!). Int J Epidemiol 44, 776-788.

14. Statistics Canada (2004) Canadian Community Health Survey. http://www23.statcan.gc.ca/imdb/p2SV.pl?Function= getSurvey\&SDDS=3226 (accessed February 2017).

15. DiaSorin (2007) The Diagnostic Specialist. http://www. zdiasorin.com/en (accessed May 2017).

16. Maunsell Z, Wright DJ \& Rainbow SJ (2005) Routine isotopedilution liquid chromatography-tandem mass spectrometry assay for simultaneous measurement of the 25-hydroxy metabolites of vitamins $\mathrm{D}_{2}$ and $\mathrm{D}_{3}$. Clin Chem 51, 1683-1690.

17. Singh RJ, Taylor RL, Reddy GS et al. (2006) C-3 epimers can account for a significant proportion of total circulating 25-hydroxyvitamin $\mathrm{D}$ in infants, complicating accurate measurement and interpretation of vitamin D status. J Clin Endocrinol Metab 91, 3055-3061.

18. Institute of Medicine (2010) Dietary Reference Intakes for Calcium and Vitamin D. Washington, DC: National Academies Press.

19. Godel JC (2007) Vitamin D supplementation: recommendations for Canadian mothers and infants. Paediatr Child Health 12, 583-589.

20. Armstrong C (2009) AAP doubles recommended vitamin D intake in children. Am Fam Physician 80, 196-198.

21. ICD10Data.com (2016) American ICD-10-CM (diagnosis) and ICD-10-PCS (procedure) medical billing codes. http://www.icd10data.com/ICD10CM/Codes/J00-J99/J00J06/J06-/J06.9 (accessed September 2016). 
22. Juurlink D, Preyra C, Croxford R et al. (2006) Canadian Institute for Health Information Discharge Abstract Database: A Validation Study. ICES Investigative Report. Toronto: Institute for Clinical Evaluative Sciences.

23. Newacheck PW (1992) Characteristics of children with high and low usage of physician services. Med Care 30, 30-42.

24. Wayse V, Yousafzai A, Mogale K et al. (2004) Association of subclinical vitamin D deficiency with severe acute lower respiratory infection in Indian children under 5 y. Eur J Clin Nutr 58, 563-567.

25. Falagas ME, Mourtzoukou EG \& Vardakas KZ (2007) Sex differences in the incidence and severity of respiratory tract infections. Respir Med 101, 1845-1863.

26. Koopman LP, Smit HA, Heijnen MA et al. (2001) Respiratory infections in infants: interaction of parental allergy, child care, and siblings - the PIAMA Study. Pediatrics 108, 943-948.

27. Dales RE, Cakmak S, Brand K et al. (2004) Respiratory illness in children attending daycare. Pediatr Pulmonol 38, 64-69.

28. Ball TM, Holberg CJ, Albous MB et al. (2002) Influence of attendance at day care on the common cold from birth through 13 years of age. Arch Pediatr Adolesc Med 156, 121-126.

29. Campitelli MA, Rosella LC \& Kwong JC (2014) The association between obesity and outpatient visits for acute respiratory infections in Ontario, Canada. Int J Obes (Lond) 38, 113-119.

30. Pietrobelli A, Faith MS, Allison DB et al. (1998) Body mass index as a measure of adiposity among children and adolescents: a validation study. J Pediatr 132, 204-210.

31. World Health Organization (2006) WHO Child Growth Standards. Methods and development: Length/height-forage, weight-for-age, weight-for-length, weight-for-height and body mass index-for-age. http://www.who. int/childgrowth/publications/technical_report_pub/en/index. html (accessed February 2017).

32. Harrell FE Jr (2001) Regression Modeling Strategies: With Applications to Linear Models, Logistic Regression and
Survival Analysis. Nashville, TN: Springer Science + Business Media, Inc.

33. Little RJA \& Rubin DB (2002) Statistical Analysis with Missing Data. Hoboken, NJ: Wiley.

34. O'Brien RM (2007) A caution regarding rules of thumb for variance inflation factors. Qual Quant 41, 673-690.

35. Zhang H, Ahn J \& Yu K (2011) Comparing statistical methods for removing seasonal variation from vitamin D measurements in case-control studies. Stat Interface $\mathbf{4}$, $85-93$.

36. To T, Guttmann A \& Dick P (2001) Atlas Report: Inpatient and Day Surgery use by Children in Ontario. Toronto: Institute for Clinical Evaluative Sciences.

37. Grant CC, Kaur S, Waymouth E et al. (2015) Reduced primary care respiratory infection visits following pregnancy and infancy vitamin D supplementation: a randomised controlled trial. Acta Paediatr 104, 396-404.

38. Grant CC, Stewart AW, Scragg R et al. (2014) Vitamin D during pregnancy and infancy and infant serum 25-hydroxyvitamin D concentration. Pediatrics $\mathbf{1 3 3}$, e143-e153.

39. Roos LL, Menec V \& Currie RJ (2004) Policy analysis in an information-rich environment. Soc Sci Med 58, 2231-2241.

40. Doiron D, Raina P \& Fortier I (2014) Linking Canadian population health data: maximizing the potential of cohort and administrative data. Can J Public Health 104, e258-e261.

41. Langlois K, Greene-Finestone L, Little J et al. (2010) Vitamin D status of Canadians as measured in the 2007 to 2009 Canadian Health Measures Survey. Health Rep 21, 47-55.

42. El Hayek J, Pham TT, Finch S et al. (2013) Vitamin D status in Montreal preschoolers is satisfactory despite low vitamin D intake. J Nutr 143, 154-160. 